\title{
Mantle dynamics in the SE Tibetan Plateau revealed by teleseismic shear-
}

\section{wave splitting analysis}

\section{Zhouchuan Huanga,*, Sébastien Chevrotb}

a. State Key Laboratory for Mineral Deposits Research, School of Earth Sciences and Engineering, Nanjing University, Nanjing, China

b. $\quad$ GET, UMR 5563, Université de Toulouse, CNRS, IRD, UPS, Toulouse, France

*Corresponding author: huangz@nju.edu.cn (Z. Huang)

\section{Highlights:}

1. We measure frequency-dependent shear wave splitting parameters in the SE Tibetan Plateau.

2. Two-layer anisotropy better explains the observations at many stations.

3. The asthenosphere beneath the plateau is extruded through the SE Tibetan Plateau.

\begin{abstract}
The tectonic evolution of the southeastern Tibetan Plateau is key to understanding the mechanism of growth of the whole Tibetan Plateau. Its imprint on lithospheric and asthenospheric mantle rock fabrics is expected to have a strong signature on seismic anisotropy. In this study, we measure the splitting delays and fast polarization directions (FPD) with the minimum-transverse-energy method using core-refracted phases (e.g., SKS, SKKS, PKS) recorded by the ChinArray experiment. The potential complex anisotropic structures, i.e., the frequency-dependent splitting and two-layer anisotropy, are investigated in particular. The FPDs are consistent in different frequency bands, but the delay times measured at low frequency $(8-20 \mathrm{~s})$ are often larger than those measured at high frequency (2-8 s). The measurements can be better explained by a two-layer anisotropy model at many
\end{abstract}


stations, which suggests different patterns of seismic anisotropy in the lithosphere and asthenosphere. In the lithosphere, anisotropy shows distinct patterns in the different tectonic blocks. The FPDs are oriented along the major tectonic boundaries. In the asthenosphere, continuous NW-SE FPDs spread from the Tibetan plateau to the Youjiang Orogen along the southwestern margin of the Yangtze craton, implying asthenospheric extrusion from the high plateau. In the northern Indochina block, the dominant E-W FPDs may indicate asthenospheric flow driven by the eastern subduction and subsequent rollback of the Indian plate.

Keywords: Shear-wave splitting; Seismic tomography; ChinArray; Two-layer anisotropy model; Tibetan Plateau; Asthenospheric extrusion

\section{Introduction}

The Tibetan Plateau results from the collision between the Indian and Eurasian Plates which started $\sim 50 \mathrm{Ma}$ (Figure 1) [Yin and Harrison, 2000; Tapponnier et al., 2001; Royden et al., 2008]. It is a major Cenozoic structure that affects the environment and climate of whole Asia [Yin and Harrison, 2000], which makes it a major focus in geosciences. Many different models were proposed to explain the growth of the Tibetan Plateau. One class of models suggests that the plateau is caused by the deformation of the whole lithosphere, produced either by plate subduction [Tapponnier et al., 2001; Kind et al., 2002] or distributed lithospheric deformation [England and Houseman, 1986]. Another kind of models emphasizes crustal deformations, in which the plateau uplift is produced by thickened upper crust (due to pure shear deformations) [Zhang et al., 2004] or lower crust (due to crustal flow) [Royden et al., 1997; Clark and Royden, 2000].

The SE Tibetan Plateau is key to understanding the tectonic evolution of the high 
plateau. It is bounded by the stable Sichuan Basin to the northeast and the eastern Himalayan syntaxis (EHS) to the southwest (Figure 1). GPS measurements indicate that the upper crust is rotating clockwise around the EHS [Zheng et al., 2017]. The derived crustal strains are generally localized near major faults such as the Lijiang-Xiaojinhe fault at the plateau margin and the large sinistral Xianshuihe-Xiaojiang fault [Kreemer et al., 2014; Zheng et al., 2017]. However, focal mechanisms indicate that the stress field in the upper crust is controlled by the gravity potential [Xu et al., 2016; Xu et al., 2020].

Many seismological studies have been conducted to reveal the deep architecture of the SE Tibetan Plateau. The crustal thickness decreases from more than $60 \mathrm{~km}$ in eastern Tibet to $30 \mathrm{~km}$ in the surrounding Yangtze and Indochina blocks to the southeast [Wang et al., 2017; Xu et al., 2020]. Seismic velocities in the mid-lower crust beneath the plateau are generally lower than those in the surrounding regions [Yao et al., 2010; Liu et al., 2014; Bao et al., 2015b]. Recent high-resolution tomography revealed two belts of low seismic velocity, high attenuation and conductivity in the lower crust, which were interpreted as channel flows in the deep crust of the SE Tibetan Plateau [Bao et al., 2015a]. Similar channel flows may also exist in the asthenosphere. Regional and teleseismic tomography imaged a low velocity zone in the upper mantle surrounding the southwestern margin of the stable, high velocity root of the Yangtze craton [Huang et al., 2015a; 2015c; Lei and Zhao, 2016]. Mantle processes may also be affected by the subduction of the Indian Plate, which was imaged as a high velocity anomaly that extends from the uppermost mantle to the mantle transition zone [Li et al., 2008; Wei et al., 2012; Xu et al., 2018].

Flow in the mantle produces a lattice preferred orientation of olivines and pyroxenes, and thus seismic anisotropy, which may be captured by seismic waves that travel through it [Silver and Chan, 1991; Mainprice, 2015; Maupin and Park, 2015]. Shear waves split into 
two quasi shear waves when they travel through an anisotropic medium [Silver and Chan, 1991]. These shear waves are orthogonally polarized and propagate with different velocities, a physical phenomenon called birefringence or shear wave splitting. Two parameters are used to describe this shear-wave splitting quantitively. The polarization of the fast wave (FPD, $\varphi$ ) indicates the orientation of the aligned fabrics in the underlying medium. The delay time $(\delta t)$ is the time-difference accumulated by the two quasi shear waves. It depends on the strength of anisotropy and on the thickness of the anisotropic layer. Crustal anisotropy beneath the SE Tibetan Plateau has been investigated intensively [Yao et al., 2010; Shi et al., 2012; Sun et al., 2012, 2016; Cai et al., 2016; Huang et al., 2018; Han et al., 2020]. The orientation of microcracks in the upper crust, revealed mainly by local shear wave splitting and surfacewave studies, are usually parallel to the strike of faults [Yao et al., 2010; Shi et al., 2012; Huang et al., 2018, Han et al., 2020]. The anisotropy in the lower crust is different. Splitting measurements performed on Pms phases indicate large delay times [Sun et al., 2012; Cai et al., 2016]. Since upper crust accounts for up to $0.1 \mathrm{~s}$ delay times, the Pms delay times $(\sim 0.3$ s) mostly reflect anisotropy in the lower crust [Han et al., 2020]. The Pms splitting FPDs beneath the high plateau are consistent with the model of deep crustal flow from the plateau to its southeast margin [Sun et al., 2012]. In contrast, recent high-resolution $\mathrm{P}$ wave anisotropic tomography found that the fast orientation is parallel to the plateau margin as well as the contour lines of the relief and Moho depths [Huang et al., 2018; Han et al., 2020; Xu et al., 2020]. These results would indicate that crustal flow has been blocked by the strong Yangtze and Indochina crustal blocks [Huang et al., 2018; Xu et al., 2020].

High-resolution seismic anisotropy in the upper mantle can be revealed by teleseismic shear wave (e.g., SKS, PKS, SKKS, hereafter XKS for short) splitting [Lev et al., 2006; Sol et al., 2007; Wang et al., 2008; Huang et al., 2014; Chang et al., 2015; Huang et al., 2015b; 
Tiwari et al., 2017; Kong et al., 2018]. The first-order pattern of XKS splitting is the clockwise rotation in the eastern Tibetan Plateau and the abrupt change of FPDs across $\sim 26^{\circ} \mathrm{N}$, from N-S in the north to E-W in the south of the SE Tibetan Plateau. This transition may be explained by a transition in the mode of deformation, from simple shear beneath the high plateau to pure shear beneath the plateau margin [Wang et al., 2008]. However, the thin lithosphere beneath south Yunnan $(<80 \mathrm{~km})$ cannot produce the observed delay times $(\sim 1.0-1.5 \mathrm{~s})$, therefore anisotropy in the asthenosphere is also required [Huang et al., 2015b]. The change of the FPDs across $26^{\circ} \mathrm{N}$ may also be explained by the asthenospheric extrusion that surrounds the southwestern margin of the stable Yangtze craton [Huang et al., 2015b; 2015c; Kong et al., 2018]. But all these studies are based on the assumption of one-layer anisotropy with horizontal symmetry axis. The potential complex anisotropic structures such as multi-layer anisotropy as discussed in the Tibetan Plateau are usually ignored. Another potential complex anisotropy is the frequency-dependent shear-wave splitting identified in subduction zones [Huang et al., 2011; Marson-Pidgeon and Savage, 1997; Wirth and Long, 2010], which may be attributed to heterogenous anisotropic structures at various scales. Huang et al. [2017] made similar observations in the northeastern Tibetan Plateau.

Poor vertical resolution of XKS splitting and coarse station distribution in this region prevent us from constraining the depth distribution of deformation in the upper mantle. In this study, we measure shear-wave splitting parameters on the XKS waves recorded by the ChinArray experiment deployed in the SE Tibetan Plateau. The measurements are analyzed in different frequency bands and fit by two-layer anisotropy models to detect possible complex anisotropic structures, especially the depth-dependent distribution of shear wave anisotropy in the upper mantle. 


\section{Data and method}

\subsection{Data}

We collected waveforms recorded by 350 broad band stations of the ChinArray project deployed in the SE Tibetan Plateau during 2011-2013 (Figure 2a). The stations are equipped with a Guralp CMG-3EPC three-component broadband seismometer and a Reftec-130 digitizer (with a sampling rate of 100 samples per second). We extracted records of events with magnitude larger than 5.8 and epicentral distances of $85^{\circ}-150^{\circ}$, from which we could obtain 173 good events (Figure 2b). A large number of events occurred in Tonga and New Zealand subduction zones. The SKS phases are clear for these earthquakes at distances of $85^{\circ}-110^{\circ}$, especially for the deep earthquakes in the mantle transition zone. Other groups of events located in North and Central America provided SKKS and PKS phases that could also be exploited at distances of $120-135^{\circ}$.

\subsection{Shear-wave splitting measurements with minimum-transverse-energy method}

In this study, we first used the SplitLab toolbox [Wüstefeld et al., 2008] and the transverse-component minimization method [Silver and Chan, 1991] to measure shear wave splitting parameters. The waveforms are filtered by a Butterworth broadband filter of 2-8 s (HF) and 8-20 s (LF), respectively. A grid-search approach is applied to find the optimal splitting parameters that minimize the energy on the corrected transverse component, which was constructed by rotating $\left(-90^{\circ}\right.$ to $90^{\circ}$ at $1^{\circ}$ step) and time-shifting ( $0 \mathrm{~s}$ to $4 \mathrm{~s}$ at $0.02 \mathrm{~s}$ step) the Q-T components in a ray-coordinate based L-Q-T coordinate system. The uncertainties are estimated by the $95 \%$ confidence region of the F-test.

We follow the semi-automatic procedure of Huang et al. [2017] to select the time windows for shear wave splitting analysis (Figure 3). We determine the beginning of the time window from the STA/LTA ratio (short-time to long-time average ratio) on the radial 
component around the theoretical arrival time of the XKS phases. The end of the time window changes iteratively from 1 to 2.5 times (with a step of 1/10 of) the dominant period after the beginning. The iterations stop if the ending falls into the window of the direct $\mathrm{S}$ wave or if the energy on the transverse component increases (see Huang et al. [2017] for details). Finally, after a visual check we rejected poor measurements (e.g., noisy data, poor correction). This semi-automatic procedure improves the reliability of the results [Huang et al., 2017] and makes it convenient to analyze shear wave splitting in different frequency bands.

\subsection{Two-layer model analysis}

We applied the grid-search algorithm of Silver \& Savage (1994) to search for the optimal two-layer anisotropy models, including the FPDs and time delays of the lower $\left(\varphi_{\mathrm{L}}, \delta \mathrm{t}_{\mathrm{L}}\right)$ and upper layers $\left(\varphi_{\mathrm{U}}, \delta \mathrm{t}_{\mathrm{U}}\right)$. The synthetic splitting parameters () can thus be calculated [Silver \& Savage, 1994]. The misfit between the synthetic and observations parameters

$$
=\sum_{i=1}^{\mathrm{N}}\left[\left(\frac{\varphi_{\mathrm{i}}^{\mathrm{obs}}-\varphi_{\mathrm{i}}^{\mathrm{syn}}}{\sigma_{\mathrm{i}}^{\varphi}}\right)^{2}+\left(\frac{\delta \mathrm{t}_{\mathrm{i}}^{\mathrm{obs}}-\delta \mathrm{t}_{\mathrm{i}}^{\mathrm{syn}}}{\sigma_{\mathrm{i}}^{\delta \mathrm{t}}}\right)^{2}\right]
$$

is minimized for the optimal models, where $\left(\varphi_{i}^{o b s}, \delta t_{i}^{o b s}\right)$ and $\left(\varphi_{i}^{s y n}, \delta t_{i}^{s y n}\right)$ are the $i$-th $(i=1 \ldots N)$ observational and synthetic parameters, respectively, $\sigma_{i}^{\varphi}$ and $\sigma_{i}^{\delta t}$ are the corresponding $95 \%$ uncertainties. $\varphi_{\mathrm{L}}$ and $\varphi_{\mathrm{U}}$ change between $0^{\circ}-180^{\circ}$ with a step of $1^{\circ} ; \delta \mathrm{t}_{\mathrm{L}}$ and $\delta t_{U}$ change between $0-2.0 \mathrm{~s}$ with a step of $0.05 \mathrm{~s}$ in the grid search. The improvement of the two-layer models over single-layer models assuming horizontal axes (Fontaine et al., 2007; Huang et al., 2017) is quantified by 


$$
R^{*}=1-\frac{\left(N_{d}-1\right)}{N_{d}-k-1} \times\left(1-\mathrm{R}^{2}\right)
$$

where $N_{d}$ is the number of observations (i.e., $2 * \mathrm{~N}$ ), and $\mathrm{k}(=4)$ is the number of model parameters, $R^{2}\left(=1-r_{2} / r_{1}\right)$ is the reduction of the misfits between observational and synthetic splitting parameters for the two-layer models $\left(r_{2}\right)$ compared with the optimal onelayer model $\left(r_{1}\right)$. We further derived the $95 \%$ uncertainties of the two-layer models such that the models generating the misfit lower than $r_{2}^{\min } *\left(1+f\left(4, N_{d}-4\right) * 4 /\left(N_{d}-4\right)\right)(f$ is the inverse of the F-distribution) are considered reliable. Parameter $R^{*}$ provides a statistic estimate to the improvement of the two-layer model although no accurate uncertainties are derived. For example $R^{*} \geq 0.2$ means the two-layer models explain more than $20 \%$ of the azimuthal variation of the splitting parameters (Fontaine et al., 2007; Walker et al., 2005); in this study we used 0.2 as the critical value for favoring a two-layer model over a single-layer model.

2.4.

$$
\frac{()()}{()}
$$

\section{Results}

\subsection{Frequency-dependent shear wave splitting}

The XKS phases are clear in both low (8-20s) and high (2-8 s) frequencies (Fig. 4). The signal-to-noise ratios are mostly greater than 10 for the "Good" and "Fair" measurements. The splitting parameters are better constrained in the high frequency than in the low frequency (Fig. 4). While the uncertainties of the FPD and delay times in the high frequency are usually smaller than $20^{\circ}$ and $0.6 \mathrm{~s}$, respectively. 
Figure 5 shows the shear wave splitting measurements with the traditional minimumtransverse-energy method [Silver and Chan, 1991] at low frequency (8-20 s), including 435 "Good" and 768 "Fair" results among a total of 9053 useful measurements after analyzing a total of 42370 records. The FPDs show a dominant transition from N-S to E-W southward across $\sim 26^{\circ} \mathrm{N}$. The delay times are mostly between 0.8 and $2.0 \mathrm{~s}$. Strong splitting delays are generally measured at stations in the southern margin of the Sichuan Basin and in the Youjiang Orogen. These shear wave splitting measurements are close to those reported in previous studies. Some differences can be noted, however, in the Tibetan Plateau (e.g., region A with NE-SW FVDs), as already noted in several previous studies [Wang et al., 2008; Chang et al., 2015; Bao et al., 2020]. We also obtained 1046 "Good" and 2626 "Fair" nulls. Their back azimuths concentrate around $30^{\circ}$ and $120^{\circ}$ directions, where most earthquakes occurred.

Figure 6 shows the shear wave splitting measurements at higher frequency $(2-8 \mathrm{~s})$, including 1108 "Good" and 1538 "Fair" measurements as well as 57 "Good" and 423 "Fair" nulls. The angular differences between the measured FPDs in the higher and lower frequencies are smaller than $20^{\circ}$ (Figure 7). However, the delay times differ significantly; the high frequency $(\sim 0.5-1.4 \mathrm{~s})$ measurements are much smaller than those at lower frequency (Figure 7c). Among the 497 splitting parameters measured in both higher (2-8 s) and lower $(8-20 \mathrm{~s})$ frequencies, the differences of 155 delay times (over $30 \%$ ) are larger than $0.5 \mathrm{~s}$. Frequency-dependent shear-wave splitting has been observed in subduction zones [Huang et al., 2011; Marson-Pidgeon and Savage, 1997; Wirth and Long, 2010]. The differences in delay times can be explained by the frequency-dependent sensitivities of XKS waves to the anisotropic structures at different scales [Marson-Pidgeon and Savage, 1997]. In the 
viewpoint of finite frequency, lower frequencies sample a wider region and yield a regional average [Eakin et al., 2015; Monteiller and Chevrot, 2011; Lin et al., 2014a, 2014b]. Figure 8 shows the sensitivity kernels of the splitting-intensity parameters for an XKS waves at periods of $10 \mathrm{~s}(\mathrm{a}, \mathrm{b})$ and $5 \mathrm{~s}(\mathrm{c}, \mathrm{d})$, respectively. At $150 \mathrm{~km}$ depth, the diameter of the sensitivity kernel at 10-s is 1.5 times that of at 5-s. In addition, forward modeling showed that the measurements in the higher frequency range are generally biased towards anisotropy at shallow depth [Saltzer et al., 2000].

Our XKS splitting measurements differ from crustal anisotropy characterized from the analysis of splitting on S and Pms phases. Local S wave splitting shows that the upper crustal FPDs are parallel to the fault strikes [Shi et al., 2012], while Pms splitting revealed different deep crustal anisotropy due to specific lower crustal deformations during the plateau expansion [Sun et al., 2012; Cai et al., 2016]. Crustal anisotropy only generates splitting delay times up to $\sim 0.3 \mathrm{~s}$, which represents only a small part of the XKS delay times (1-1.5 s) at low frequency but can account for $50 \%$ of the XKS delay times at high frequency. Consequently, XKS splitting especially for those in lower frequency is mainly caused by anisotropy in the upper mantle. The strong crustal small-scale heterogeneity may produce only a small coherent contribution to apparent splitting at low frequency.

\subsection{Two-layer models}

We fit the shear wave splitting measurements at every station with two-layer anisotropy models; Figure 9 shows an example. The two-layer models can better explain the azimuthal variations of splitting parameters in the higher frequency band at 28 stations (Figure 10, blue and red rose diagrams). However, the two-layer models only significantly improve the measurements in the lower frequency at 3 stations (Figure 10, cyan and pink rose 
diagrams); they are similar to the two-layer models for high-frequency measurements at the adjacent stations. As mentioned above, the low-frequency XKS waves have large sensitivity kernels and they capture the longer wavelength anisotropic structures. Thus lateral structural variations may destroy the possible azimuthal variation of the splitting parameters produced by a two-layer model.

In these two-layer models, the FPDs of the lower layer are generally NW-SE. Nevertheless, at station 53033 to the northeast of the Tengchong volcano, the lower-layer FPDs are NEE-SWW to nearly E-W. Kong et al. [2018] analyzed the shear splitting at permanent stations in the SE Tibetan Plateau. They obtained the similar E-W FPDs in the lower layer at stations in the northern Indochina and the Red-River fault zone (Figure 10).

The FPDs of the upper layer show strong lateral variations (Figure 10). They are NW-SE to N-S and parallel to the strikes of faults in the Tibetan Plateau. In the southern margin of the Sichuan Basin, the upper-layer and lower-layer FPDs are not well discriminated actually, both NW-SE. At station 53231, the upper-layer FPDs rotate to be nearly N-S, which are consistent to the fault strikes. In the northern Indochina and Red-River fault zone, the FPDs are nearly N-S. In the Youjiang Orogen, the FPDs are mostly E-W.

3.3.

\section{Discussion}

\subsection{Lithospheric anisotropy}

The SE Tibetan Plateau consists of many blocks with different sizes and vertical extents. To first order, the tectonics of the region is dominated by the interactions between the stable Yangtze craton, the Indochina blocks, and a series of sub-blocks belonging to the 
Tibetan Plateau (Figure 2a) [Royden et al., 2008]. The Youjiang Orogen is amalgamated with the Yangtze craton along the southern margin and collided with the Indochina block along the Red-River faults zone during the closure of the Paleo-Tethyan ocean in the Mesozoic [Yang et al., 2012; Faure et al., 2014; Qiu et al., 2016]. The southeast Chuandian block (among Lijiang-Xiaojinhe, Red-River, and Xiaojiang faults) is the southwestern part of the Yangtze craton but it has been involved in the active tectonics of the SE Tibetan Plateau.

The present study only covers the SE margin of the Tibetan Plateau. The shear-wave splitting measurements show fault-parallel FPDs in general (Figures 5-7), in particular in the upper-layer of two-layer models (Figure 10). Thus they mainly arise from the lithospheric deformations caused by the northeast subduction/collision of the eastern Himalayan syntax. Along the southeastern plateau margin, there are many NE-SW FPDs, which are parallel to the plateau margin (A and B in Figures 5-7). These results obviously reflect the anisotropy in the shallow part, as can be inferred from our synthetic tests. They are therefore caused by the lithospheric deformations due to the interaction between the Tibet Plateau and the Yangtze craton [e.g., Bao et al., 2020].

The lithospheric anisotropy of the Yangtze craton is relatively simple. The lithospheric thickness in the core of the Yangtze craton beneath the Sichuan Basin is $\sim 200 \mathrm{~km}$ [Pasyanos et al., 2014]. The NW-SE FPDs spread in the whole lithosphere (Figures 5-7), mostly representing the fossil anisotropy frozen in the lithosphere. Similar processes may explain the E-W FPDs along the southern margin of the Yangtze carton where the Youjiang Orogen is amalgamated to form the South China block in the Triassic [Yang et al., 2012; Faure et al., 2014; Qiu et al., 2016]. The E-W FPDs are generally parallel to the boundary 
between the Youjiang Orogen and Yangtze craton and likely developed during the block amalgamation.

The Red-River fault zone along the southwestern margin of the South China block (including Yangtze craton and Youjiang Orogen) was previously part of the Mesozoic suture zone between the South China and Indochina blocks [Faure et al., 2014]. It was then reactivated as a strike-slip fault during the Indo-Asian collision and the simultaneous plateau growth [Tapponnier et al., 1982; 2001]. The fault-parallel FPDs (i.e., NW-SE) especially of the upper layer (Figure 10) well reflect the aligned mineral fabrics along the tectonic boundary. The weak lithospheric anisotropy beneath the northern Indochina block may result from the small thickness of the lithosphere $\sim 60-80 \mathrm{~km}$ [Pasyanos et al., 2014; Hu et al., 2015].

\subsection{Asthenospheric extrusion/flow}

The anisotropy of the lower-layer allows us to distinguish two domains. The first domain is the continuous NW-SE FPDs along the southwestern margin of the Yangtze cratonic root (Figure 10). We propose that the NW-SE FPDs represent the asthenospheric extrusion/flow from the Tibetan Plateau. Seismic tomography indicates northward Indian subduction and southward Eurasian subduction beneath the high plateau [Li et al., 2008; Wei et al., 2012; Huang et al., 2015a]. The asthenospheric space is largely shrunk so that the asthenosphere is thickened vertically while extruded through mantle channelling along the plateau margin. The SE Tibetan Plateau margin is probably the best region to observe the effect of asthenospheric extrusion because the other margins mostly involve stable blocks (e.g., Tarim, Ordos, Sichuan blocks) [Huang and Zhao, 2006; Wei et al., 2012]. This is in

good agreement with surface wave tomography, which clearly imaged a thickened 
asthenospheric channel under the SE Tibetan Plateau [Zhang et al., 2014]. Another factor leading to the asthenospheric flow is an $80 \mathrm{~km}$ step at the bottom of the lithosphere. The lithospheric thickness beneath the Chuandian block and Youjiang Orogen is less than $80 \mathrm{~km}$, in great contrast to $>160 \mathrm{~km}$ lithosphere beneath the Sichuan Basin (Figure 11a) [Pasyanos et al., 2014; Hu et al., 2015]. Consequently, the asthenospheric material may be extruded around the southwestern margin of the cratonic root. Seismic tomography revealed much lower velocities around the southwestern cratonic margin (Figure 11b) [Huang et al., 2015c; 2019; Lei et al., 2019], supporting possible asthenospheric extrusion.

The second group of anisotropy is the dominant E-W FPDs extending from northern Indochina block to Youjiang Orogen (Figure 10). The E-W FPDs are mainly caused by the mantle flow related to the eastward subduction of the Indian plate which has been clearly revealed by tomographic studies [Wei et al., 2012; Huang et al., 2015a; Lei et al., 2019]. The northern Indochina and Youjiang blocks are characterized by very thin lithosphere and low velocities in the upper mantle (Figure 11) [Pasyanos et al., 2014; Huang et al., 2015c, 2019], indicating that they are heavily affected by the Indian subduction and subsequent rollback. The regional mantle-wedge flow may be responsible for the E-W mineral fabrics and anisotropy in the upper mantle [Huang et al., 2015b; Kong et al., 2018]. Geophysical and geochemistry results also suggest lithospheric delamination and asthenospheric upwelling in northern Indochina [Chung et al., 1997; Lu et al., 2013; Chen et al., 2017; Wang et al., 2018]. The upwelling may in fact break the horizontal mineral alignment resulting in weaker anisotropy. These predictions are consistent with the observed smaller XKS splitting delay times in this region (Figure 5-7). 
The two domains of deep asthenospheric anisotropy merge in the eastern Youjiang Orogen (Figure 11) while eastward flow is observed beneath eastern China. Regional seismic tomography together with XKS splitting in Southeast Asia imply that the mantle flow may reach the northwestern margin of the South China Sea [Wei et al., 2012; Huang et al., 2015a; 2015b]. This regional mantle flow may contribute to the volcanism in Hainan and southern Vietnam and possibly affect the evolution of the South China Sea (see [Huang et al., 2015a] for details).

\section{Conclusions}

1. We characterized shear wave splitting in the SE Tibetan Plateau using XKS waves recorded by the dense ChinArray experiment. The measurements show a dominant change of the FPDs across $26^{\circ} \mathrm{N}$, i.e., from N-S in the north to $\mathrm{E}-\mathrm{W}$ in the south, in good agreement with previous studies. We measured the shear-wave splitting in two different frequency bands (2-8 $\mathrm{s}$ and 8-20 s) with the Silver and Chan technique, which give similar FPDs but the delay times measured at 2-8 s are smaller than those at 8-20 s. Moreover, the azimuthal variations of the FPDs at many stations can be better explained by two-layer anisotropy models.

2.

3. In the lithosphere, the FPDs in the different blocks show different orientations: N-S to NW-SE in the Tibetan Plateau, NW-SE in the Yangtze craton (Sichuan Basin), and $\mathrm{E}-\mathrm{W}$ in northern Indochina. The distribution of seismic anisotropy seems to be controlled by the main tectonic boundaries, with NE-SW FPDs along the TibetYangtze boundary, NW-SE FPDs along the Indochina-Yangtze boundary, and E-W FPDs along the Yangtze-Youjiang orogens. These results indicate that lithospheric 
anisotropies are mainly produced by past and present deformations in the lithosphere. In the asthenosphere, the shear wave anisotropy suggests two channels of asthenospheric flow. One channel extends from the Tibetan Plateau to eastern Youjiang, characterized as NW-SE FPDs, indicating southeastern asthenospheric extrusion along the southwestern margin of the Yangtze cratonic root at depth. Another channel extends from northern Indochina to Youjiang Orogen eastward, characterized as E-W FPDs, resulting from the mantle flow driven by the eastern subduction of the Indian plate.

Acknowledgements. The waveform data used in this study were provided by the China Seismic Array Data Management Center at the Institute of Geophysics, China Earthquake Administration (ChinArray DMC, doi:10.12001/ChinArray.Data, http:// www.chinarraydmc.cn/). We thank Prof. M. Savage (the Editor), the Associate Editor, Prof. Tuna Eken, and two anonymous reviewers for their constructive comments and suggestions. This work was supported by the National Natural Science Foundations of China (41674044) and by the ChinArray Program (DQJB16A0306). ZH is also supported by the Deng-Feng Scholar Program of Nanjing University. Most figures were made using GMT [Wessel et al., 2019].

\section{References}

Argus, D. F., R. G. Gordon, and C. DeMets (2011), Geologically current motion of 56 plates relative to the no-net-rotation reference frame, Geochemistry, Geophysics, Geosystems, 12(11), Q11001.

Bao, X., X. Sun, M. Xu, D. W. Eaton, X. Song, L. Wang, Z. Ding, N. Mi, H. Li, D. Yu, Z. Huang, and P. Wang (2015a), Two crustal low-velocity channels beneath SE Tibet revealed by joint inversion of Rayleigh wave dispersion and receiver functions, Earth and Planetary Science Letters, 415, 16-24. 
Bao, X., X. Song, and J. Li (2015b), High-resolution lithospheric structure beneath Mainland China from ambient noise and earthquake surface-wave tomography, Earth and Planetary Science Letters, 417, 132-141.

Bao, X., X. Song, D. W. Eaton, Y. Xu, and H. Chen (2020), Episodic Lithospheric Deformation in Eastern Tibet Inferred From Seismic Anisotropy, Geophysical Research Letters, 47(3), B05308.

Cai, Y., J. Wu, L. Fang, W. Wang, and S. Yi (2016), Crustal anisotropy and deformation of the southeastern margin of the Tibetan Plateau revealed by Pms splitting, Journal of Asian Earth Sciences, 121, 120-126.

Chang, L., Z. Ding, and C. Wang (2015), Upper mantle anisotropy beneath the southern segment of North-South tectonic belt, Chinese Journal of Geophysics, 58, 4052-4067.

Chen, B., X. Long, S. A. Wilde, C. Yuan, Q. Wang, X. Xia, and Z. Zhang (2017), Delamination of lithospheric mantle evidenced by Cenozoic potassic rocks in Yunnan, SW China: A contribution to uplift of the Eastern Tibetan Plateau, Lithos, 284-285, 709729.

Chevrot, S. (2000), Multichannel analysis of shear wave splitting, Journal of Geophysical Research: Solid Earth, 105(B9), 21579-21590.

Chung, S.-L., T.-Y. Lee, C.-H. Lo, P.-L. Wang, C.-Y. Chen, N. T. Yem, T. T. Hoa, and W. Genyao (1997), Intraplate extension prior to continental extrusion along the Ailao ShanRed River shear zone, Geology, 25(4), 311-314.

Clark, M. K., and L. H. Royden (2000), Topographic ooze: Building the eastern margin of Tibet by lower crustal flow, Geology, 28(8), 703-706.

Eakin, C. M., M. D. Long, L. S. Wagner, S. L. Beck, and H. Tavera (2015), Upper mantle anisotropy beneath Peru from SKS splitting: Constraints on flat slab dynamics and interaction with the Nazca Ridge, Earth and Planetary Science Letters, 412, 152-162.

England, P., and G. Houseman (1986), Finite strain calculations of continental deformation: 2. Comparison with the India-Asia Collision Zone, Journal of Geophysical Research: Solid Earth, 91(B3), 3664-3676.

Faure, M., C. Lepvrier, V. V. Nguyen, T. V. Vu, W. Lin, and Z. Chen (2014), The South China block-Indochina collision: Where, when, and how? Journal of Asian Earth Sciences, 79, 260-274.

Favier, N., and S. Chevrot (2003), Sensitivity kernels for shear wave splitting in transverse isotropic media, Geophysical Journal International, 153(1), 213-228

Fontaine, F. R., G. Barruol, A. Tommasi, and G. H. R. Bokelmann (2007), Upper-mantle flow beneath French Polynesia from shear wave splitting, Geophysical Journal International, 170(3), 1262-1288.

Guo, J.-L. et al. (2014), 3.45 Ga granitic gneisses from the Yangtze Craton, South China: Implications for Early Archean crustal growth, Precambrian Research, 242, 82-95.

Han, C., M. Xu, Z. Huang, L. Wang, M. Xu, N. Mi, D. Yu, T. Gou, H. Wang, S. Hao, M. Tian, and Y. Bi (2020), Layered crustal anisotropy and deformation in the SE Tibetan plateau revealed by Markov-Chain-Monte-Carlo inversion of receiver functions, Physics of the Earth and Planetary Interiors, 306, 106522.

Hu, J., H. Yang, G. Li, and H. Peng (2015), Seismic upper mantle discontinuities beneath Southeast Tibet and geodynamic implications, Gondwana Research, 28(3), 1032-1047.

Huang, J., and D. Zhao (2006), High-resolution mantle tomography of China and surrounding regions, Journal of Geophysical Research: Solid Earth, 111(B9), 63, B09305. 
Huang, Z., D. Zhao, and L. Wang (2011), Frequency-dependent shear-wave splitting and multilayer anisotropy in northeast Japan. Geophysical Research Letters, 38, L08302.

Huang, Z., D. Zhao, and L. Wang (2015a), P wave tomography and anisotropy beneath Southeast Asia: Insight into mantle dynamics, Journal of Geophysical Research: Solid Earth, 120(7), 5154-5174.

Huang, Z., F. Tilmann, M. Xu, L. Wang, Z. Ding, N. Mi, D. Yu, and H. Li (2017), Insight into NE Tibetan Plateau expansion from crustal and upper mantle anisotropy revealed by shear-wave splitting, Earth and Planetary Science Letters, 478, 66-75.

Huang, Z., L. Wang, M. Xu, and D. Zhao (2018), P Wave Anisotropic Tomography of the SE Tibetan Plateau: Evidence for the Crustal and Upper-Mantle Deformations, Journal of Geophysical Research: Solid Earth, 123(10), 8957-8978.

Huang, Z., L. Wang, M. Xu, D. Zhao, N. Mi, and D. Yu (2019), P and S Wave Tomography Beneath the SE Tibetan Plateau: Evidence for Lithospheric Delamination, Journal of Geophysical Research: Solid Earth, 124(10), 10292-10308.

Huang, Z., L. Wang, M. Xu, Z. Ding, Y. Wu, P. Wang, N. Mi, D. Yu, and H. Li (2015b), Teleseismic shear-wave splitting in SE Tibet: Insight into complex crust and uppermantle deformation, Earth and Planetary Science Letters, 432, 354-362.

Huang, Z., P. Wang, D. Zhao, L. Wang, and M. Xu (2014), Three-dimensional P wave azimuthal anisotropy in the lithosphere beneath China, Journal of Geophysical Research: Solid Earth, 119(7), 5686-5712.

Huang, Z., P. Wang, M. Xu, L. Wang, Z. Ding, Y. Wu, M. Xu, N. Mi, D. Yu, and H. Li (2015c), Mantle structure and dynamics beneath SE Tibet revealed by new seismic images, Earth and Planetary Science Letters, 411, 100-111.

Kind, R., X. Yuan, J. Saul, D. Nelson, S.V. Sobolev, J. Mechie, W. Zhao, G. Kosarev, J. Ni, U. Achauer, M. Jiang (2002), Seismic images of crust and upper mantle beneath Tibet: Evidence for Eurasian plate subduction, Science, 298(5596), 1219-1221.

Kong, F., J. Wu, L. Liu, K. H. Liu, J. Song, J. Li, and S. S. Gao (2018), Azimuthal anisotropy and mantle flow underneath the southeastern Tibetan Plateau and northern Indochina Peninsula revealed by shear wave splitting analyses, Tectonophysics, 747, 68-78.

Kreemer, C., G. Blewitt, and E. C. Klein (2014), A geodetic plate motion and Global Strain Rate Model, Geochemistry, Geophysics, Geosystems, 15(10), 3849-3889.

Lei, J., and D. Zhao (2016), Teleseismic P-wave tomography and mantle dynamics beneath Eastern Tibet, Geochemistry, Geophysics, Geosystems, 17(5), 1861-1884.

Lei, J., D. Zhao, X. Xu, Y.-G. Xu, and M. Du (2019), Is there a big mantle wedge under eastern Tibet? Physics of the Earth and Planetary Interiors, 292, 100-113.

Lev, E., M. D. Long, and R. D. van der Hilst (2006), Seismic anisotropy in Eastern Tibet from shear wave splitting reveals changes in lithospheric deformation, Earth and Planetary Science Letters, 251(3-4), 293-304.

Li, C., R. D. van der Hilst, A. S. Meltzer, and E. R. Engdahl (2008), Subduction of the Indian lithosphere beneath the Tibetan Plateau and Burma, Earth and Planetary Science Letters, 274(1-2), 157-168.

Lin Y. P., L. Zhao, and S. H. Huang (2014a), Full-wave effects on shear wave splitting, Geophysical Research Letters, 41, 799-804.

Lin, Y. P., L. Zhao, and S. H. Hung (2014b), Full-wave multiscale anisotropy tomography in Southern California, Geophysical Research Letters, 41(24), 8809-8817. 
Liu, Q. Y., R. D. van der Hilst, Y. Li, H. J. Yao, J. H. Chen, B. Guo, S. H. Qi, J. Wang, H. Huang, and S. C. Li (2014), Eastward expansion of the Tibetan Plateau by crustal flow and strain partitioning across faults, Nature Geosci, 7(5), 361-365.

Lu, Y. J., R. Kerrich, T.C. Mccuaig, Z. Li, C. J. Hart, P. A. Cawood, Z. Hou, L. Bagas, J. Cliff, E.A. Belousova, S. Tang (2013), Geochemical, Sr-Nd-Pb, and Zircon Hf-O Isotopic Compositions of Eocene-Oligocene Shoshonitic and Potassic Adakite-like Felsic Intrusions in Western Yunnan, SW China: Petrogenesis and Tectonic Implications, Journal of Petrology, 54(7), 1309-1348.

Mainprice, D. (2015), Seismic Anisotropy of the Deep Earth from a Mineral and Rock Physics Perspective, in Treatise on Geophysics: Second Edition, vol. 2, pp. 487-538, Elsevier.

Marson-Pidgeon, K., and M. Savage (1997), Frequency-dependent anisot- ropy in Wellington, New Zealand, Geophys. Res. Lett., 24, 3297-3300.

Maupin, V., and J. Park (2015), Theory and Observations - Seismic Anisotropy, in Treatise on Geophysics: Second Edition, vol. 1, pp. 277-305, Elsevier.

Monteiller, V., and S. Chevrot (2011), High-resolution imaging of the deep anisotropic structure of the San Andreas Fault system beneath southern California, Geophysical Journal International, 186(2), 418-446.

Pasyanos, M. E., T. G. Masters, G. Laske, and Z. Ma (2014), LITHO1.0: An updated crust and lithospheric model of the Earth, Journal of Geophysical Research: Solid Earth, 119(3), 2153-2173.

Qiu, L., D.-P. Yan, S.-L. Tang, Q. Wang, W.-X. Yang, X. Tang, and J. Wang (2016), Mesozoic geology of southwestern China: Indosinian foreland overthrusting and subsequent deformation, Journal of Asian Earth Sciences, 122, 91-105.

Royden, L. H., B. C. Burchfiel, and R. D. van der Hilst (2008), The geological evolution of the Tibetan plateau, Science, 321(5892), 1054-1058.

Royden, L. H., B. C. Burchfiel, R. W. King, E. Wang, Z. L. Chen, F. Shen, and Y. P. Liu (1997), Surface deformation and lower crustal flow in eastern Tibet, Science, 276(5313), $788-790$.

Saltzer, R., J. Gaherty, and T. Jordan (2000), How are vertical shear wave splitting measurements affected by variations in the orientation of azi- muthal anisotropy with depth? Geophysical Journal International, 141, 374-390.

Shi, Y., Y. Gao, Y. Su, and Q. Wang (2012), Shear-wave splitting beneath Yunnan area of Southwest China, Earthquake Science, 25(1), 25-34.

Silver, P. G., and M. K. Savage (1994), The Interpretation of Shear-Wave Splitting Parameters In the Presence of Two Anisotropic Layers, Geophysical Journal International, 119(3), 949-963.

Silver, P. G., and W. W. Chan (1991), Shear-Wave Splitting and Subcontinental Mantle Deformation, Journal of Geophysical Research: Solid Earth, 96(B10), 16429-16454.

Sol, S., A. Meltzer, R. Burgmann, R.D. van der Hilst, R. King, Z. Chen, P.O. Koons, E. Lev, Y. Liu, P. Zeitler, X. Zhang, J. Zhang, B. Zurek (2007), Geodynamics of the southeastern Tibetan Plateau from seismic anisotropy and geodesy, Geology, 35(6), 563-566.

Styron, R., M. Taylor, and K. Okoronkwo (2010), Database of Active Structures From the Indo-Asian Collision, Eos, Transactions American Geophysical Union, 91(20), 181-182. 
Sun, S., S. Ji, K. Mihibayashi, and M. Salisbury (2016), Effects of olivine fabric, melt-rock reaction, and hydration on the seismic properties of peridotites: Insight from the Luobusha ophiolite in the Tibetan Plateau, , 121, 1-24.

Sun, Y., F. Niu, H. Liu, Y. Chen, and J. Liu (2012), Crustal structure and deformation of the SE Tibetan plateau revealed by receiver function data, Earth and Planetary Science Letters, 349, 186-197.

Tapponnier, P., G. Peltzer, A. Y. Ledain, R. Armijo, and P. Cobbold (1982), Propagating Extrusion Tectonics in Asia - New Insights From Simple Experiments with Plasticine, Geology, 10(12), 611-616.

Tapponnier, P., Z. Q. Xu, F. Roger, B. Meyer, N. Arnaud, G. Wittlinger, and J. S. Yang (2001), Oblique stepwise rise and growth of the Tibet plateau, Science, 294(5547), 16711677.

Walker, K. T., G. H. R. Bokelmann, S. L. Klemperer, and G. Bock (2005), Shear-wave splitting around the Eifel hotspot: evidence for a mantle upwelling, Geophysical Journal International, 163(3), 962-980.

Wang, C. Y., L. M. Flesch, P. G. Silver, L.-J. Chang, and W. W. Chan (2008), Evidence for mechanically coupled lithosphere in central Asia and resulting implications, Geology, 36(5), 363-366.

Wang, W., J. Wu, L. Fang, G. Lai, and Y. Cai (2017), Crustal thickness and Poisson's ratio in southwest China based on data from dense seismic arrays, Journal of Geophysical Research: Solid Earth, 122(9), 7219-7235.

Wang, X., X. Yao, S. Wang, X. Zhu, J. Wang, and C. Wang (2018), Intraplate extension of the Indochina plate deduced from 26 to 24 Ma A-type granites and tectonic implications, International Geology Review, 61(14), 1691-1705.

Wei, W., J. Xu, D. Zhao, and Y. Shi (2012), East Asia mantle tomography: New insight into plate subduction and intraplate volcanism, Journal of Asian Earth Sciences, 60, 88-103.

Wessel, P., J. F. Luis, L. Uieda, R. Scharroo, F. Wobbe, W. H. F. Smith, and D. Tian (2019), The Generic Mapping Tools Version 6, Geochemistry, Geophysics, Geosystems, 2019, 20, 5556-5564.

Wirth, E., and M. D. Long (2010), Frequency-dependent shear wave split- ting beneath the Japan and Izu-Bonin subduction zones, Phys. Earth Planet. Inter., 181, 141-154.

Wüstefeld, A., G. Bokelmann, C. Zaroli, and G. Barruol (2008), SplitLab: A shear-wave splitting environment in Matlab, Computers \& Geosciences, 34(5), 515-528.

Xu, M., H. Huang, Z. Huang, P. Wang, L. Wang, M. Xu, N. Mi, H. Li, D. Yu, and X. Yuan (2018), Insight into the subducted Indian slab and origin of the Tengchong volcano in SE Tibet from receiver function analysis, Earth and Planetary Science Letters, 482, 567579.

Xu, M., Z. Huang, L. Wang, M. Xu, Y. Zhang, N. Mi, D. Yu, and X. Yuan (2020), Sharp lateral Moho variations across the SE Tibetan margin and their implications for plateau growth, J. Geophys. Res.: Solid Earth, 125(5), e2019JB018117.

Xu, Z., Z. Huang, L. Wang, M. Xu, Z. Ding, P. Wang, N. Mi, D. Yu, and H. Li (2016), Crustal stress field in Yunnan: implication for crust-mantle coupling, Earthquake Science, 29(2), $105-115$.

Yang, J., P. A. Cawood, Y. Du, H. Huang, and L. Hu (2012), Detrital record of Indosinian mountain building in SW China: Provenance of the Middle Triassic turbidites in the Youjiang Basin, Tectonophysics, 574-575, 105-117. 
Yao, H., R. D. van der Hilst, and J.-P. Montagner (2010), Heterogeneity and anisotropy of the lithosphere of SE Tibet from surface wave array tomography, Journal of Geophysical Research: Solid Earth, 115(12), B12307.

Yin, A., and T. M. Harrison (2000), Geologic evolution of the Himalayan-Tibetan orogen, Annual Review of Earth and Planetary Sciences, 28, 211-280.

Zhang, P. Z., Z. Shen, M. Wang, W. J. Gan, R. Burgmann, and P. Molnar (2004), Continuous deformation of the Tibetan Plateau from global positioning system data, Geology, 32(9), 809-812.

Zhang, X., J. Teng, R. Sun, F. Romanelli, Z. Zhang, and G. F. Panza (2014), Structural model of the lithosphere-asthenosphere system beneath the Qinghai-Tibet Plateau and its adjacent areas, Tectonophysics, 634, 208-226.

Zheng, G., H. Wang, T. J. Wright, Y. Lou, R. Zhang, W. Zhang, C. Shi, J. Huang, and N. Wei (2017), Crustal Deformation in the India-Eurasia Collision Zone From 25 Years of GPS Measurements, Journal of Geophysical Research: Solid Earth, 122(11), 9290-9312.

Zheng, J., W. L. Griffin, S. Y. O'Reilly, M. Zhang, N. Pearson, and Y. Pan (2006), Widespread Archean basement beneath the Yangtze craton, Geology, 34(6), 417-420.

\section{Figure captions:}

1. Tectonic setting of the Tibetan Plateau. The blue square shows the location of the study region. Purple lines denote the suture zones. Red, blue and gray lines denote the thrust, sinistral and dextral faults, respectively [Styron et al., 2010]. The red triangle denotes the active Tengchong (TC) volcano. EHS: the eastern Himalayan syntaxis, RRF: the RedRiver fault.

2. Data used in the study. (a) Blue squares show 350 ChinArray stations deployed during 2010-2013. Purple and black lines denote major tectonic boundaries and active faults, respectively. EHS: the eastern Himalayan syntaxis. (b) Red circles denote the events used in the study. Purple lines denote the plate boundaries.

3. Example of a good non-null in lower (upper panel), higher frequency (middle panel) and null (lower panel) measurements using the semi-automatic methods described in Huang et al. [2017]. The six sub-figures are: (a) Information of the data and result. (b) Initial radial (dashed blue) and transverse (solid red) components. Dashed vertical line denote the synthetic arrival of the SKS phase. Two vertical lines denote the start and end 
(iteratively moved in the dark grey region) of the picked SKS window. (c) Shear wave splitting measurements in 7 iterations. White dots and short bars denote the splitting parameters and their uncertainties, respectively, in each iteration. Gray dots show the estimated polarization direction. Blue symbols denote the best splitting parameters among all the 7 iterations. (d) Initial (dashed) and corrected (solid) particle motions before and after shear wave splitting corrections. (e) Corrected radial (dashed) and transverse (solid) components. (f) The distribution of the energy on the transverse component in grid search. The shaded region in bold line denote the uncertainties defined by $95 \%$ confidence in F-test.

4. Comparison of dominant periods $(a, e)$, signal-to-noise ratio $(b, f)$, uncertainties of the FPDs (c, g) and delay times $(\mathrm{d}, \mathrm{h})$ of the "Good" and "Fair" measurements in the lower (upper panel) and higher (lower panel) frequency measurements.

5. Shear wave splitting measurements obtained using the transverse-component minimization method at lower frequency (8-20 s) [Silver and Chan, 1991]. (a) Red and blue bars denote the good and fair non-null measurements. Their orientations and lengths denote the fast polarization directions (FPD) and delay times (scale shown in bottom right), respectively. Yellow bars denote the previous results [Chang et al., 2015]. Labels A and B mark two regions with NE-SW FPDs along the Tibet-Yangtze boundary. The red triangle denotes the Tengchong volcano. The black lines denote the active faults. The black arrow denotes the absolute plate-motion directions of the eastern Himalayan syntaxis (EHS) in the NNR-MORVEL56 model [Argus et al., 2011]. (b) Histograms of the delay times for the good (red) and fair (blue) measurements. (c) Histograms of the back-azimuths for the good (red) and fair (blue) nulls.

6. The same as Figure 5 for at higher frequency (2-8 s). 
7. (a) Comparison of the splitting parameters measured at higher (blue bars) and lower frequency (red bars). Only the "Good" non-null results for both higher and lower frequency measurements are compared. (b) and (c) Comparisons of the FPDs and delay times. Red circles with short bars denote the "Good" results shown in (a). Black circles denote the results with the measurement either in higher or lower frequency marked as "Fair" non-null.

8. The Frechet kernels of shear wave splitting-intensity parameters $\left(\gamma_{c}\right.$ and $\left.\gamma_{s}\right)$ for an SKS phase (see Chevrot [2000], Favier and Chevrot [2003] for details) with back-azimuth of $135^{\circ}$ and incidence of $10^{\circ}$. (a, b) and (c, d) show the cross-sections for SKS phase at periods of $10 \mathrm{~s}$ and $5 \mathrm{~s}$, respectively.

9. The XKS splitting measurements at higher frequency at station 52046 modeled by twolayer anisotropy. (a, b) FPDs and delay times, as well as their uncertainties, plotted against the initial polarization projected to $0^{\circ}-90^{\circ}$. The yellow stars denote the synthetic distribution of the splitting parameters determined with the optimal model of two-layer anisotropy. (c, d) Distribution of the best FPDs and delay times of the upper (red) and lower (blue) layers in $95 \%$ confidence level. The red and blue bars denote the optimal FPDs and delay times of the lower and upper layers, respectively.

10. Rose diagrams show the models of two-layer anisotropy obtained in this study. Blue and red diagrams show the distribution of the FPDs of the lower and upper layers, respectively, in 95\% confidence level. Blue and red bars denote the two-layer models determined by Kong et al. [2018] with the scale for delay times shown at the bottom.

11.

12.

13. 
14.

15.

16. Comparison of lower-layer anisotropy with (a) lithospheric thickness [Pasyanos et al., 2014] and (b) $P$ wave velocity anomalies at $160 \mathrm{~km}$ [Huang et al., 2019]. Blue rose diagrams and bars show the FPDs of the lower-layer anisotropy. The background colors show the lithospheric thickness and $\mathrm{P}$ wave velocity anomalies with scale shown at the bottom. Two large arrows denote possible asthenospheric extrusion/flow in the SE Tibetan Plateau. CDB: Chuandian block. 
Figure 1

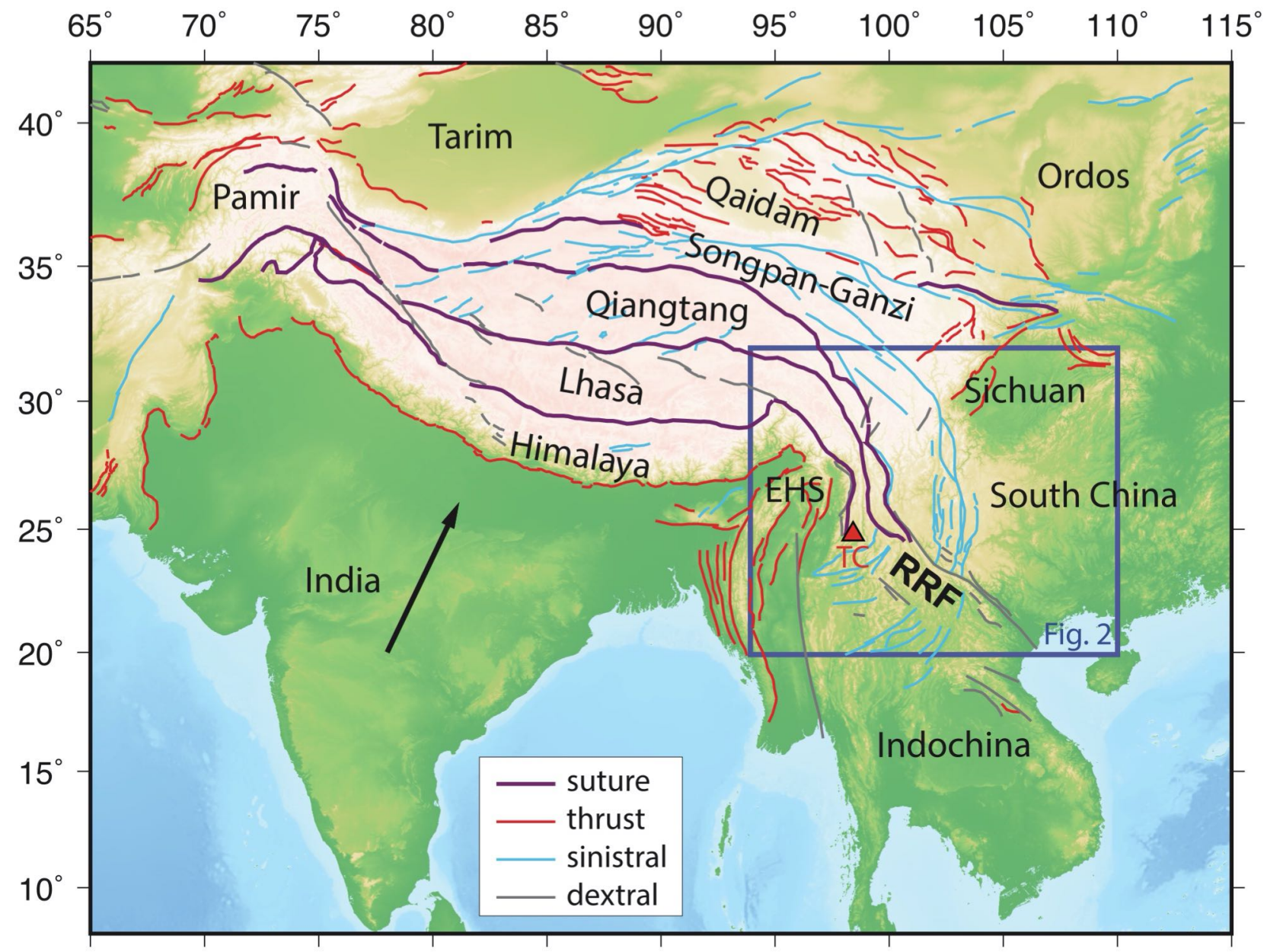


Figure 2

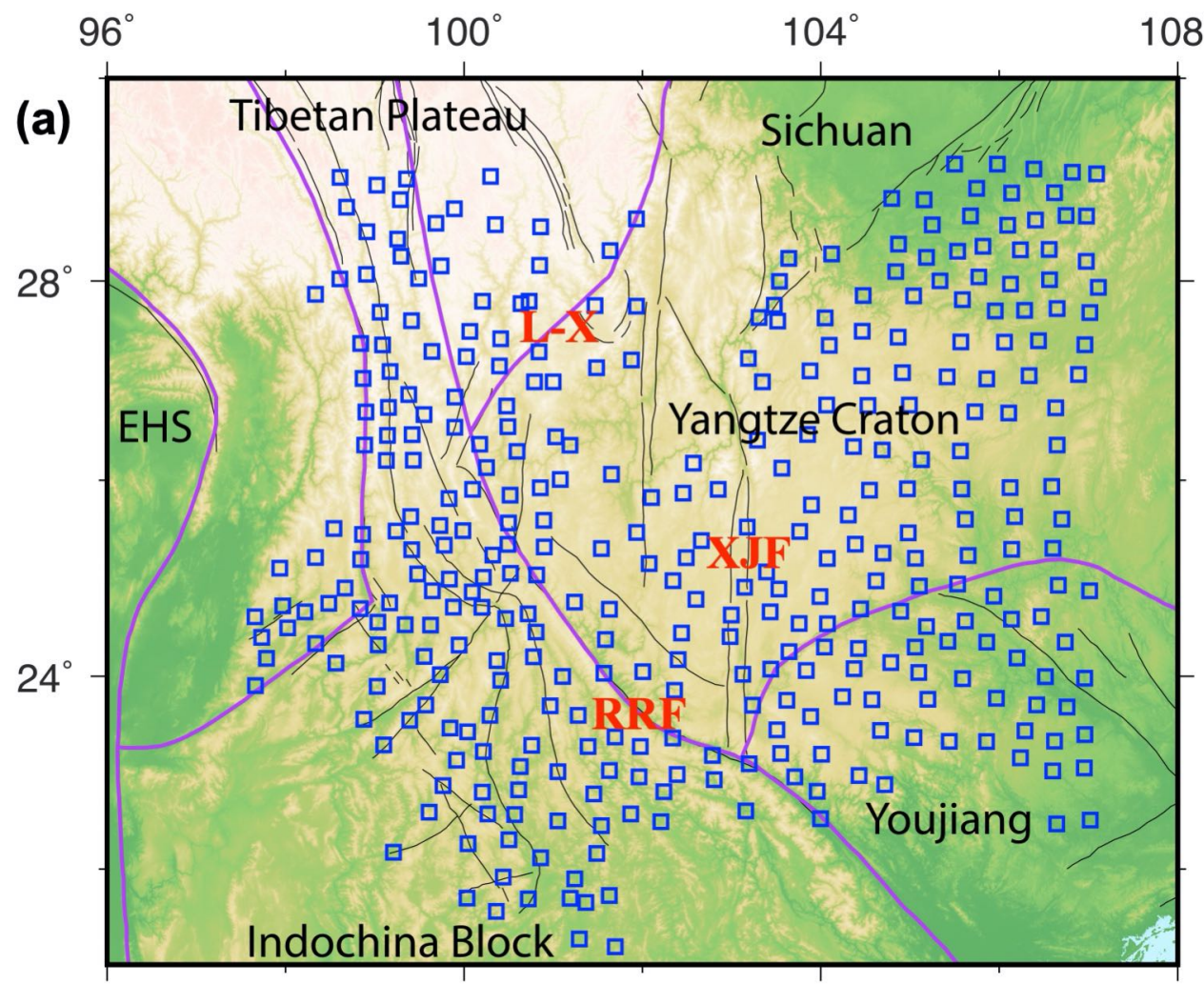

(b)

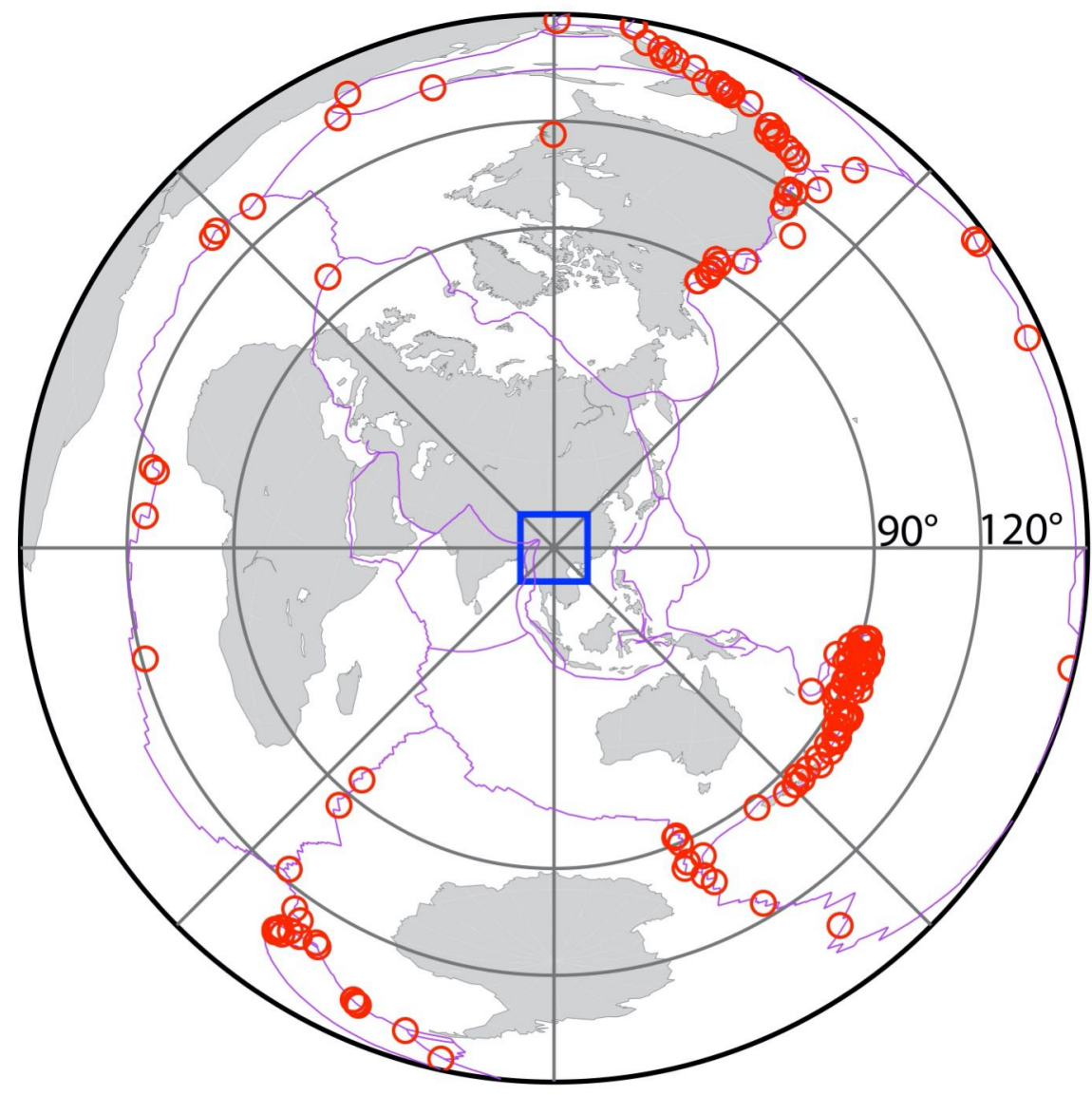


(a)

x1.4510 $\left(24.35^{\circ}, 106.74^{\circ}\right)$

20130722(203)07:01:42.7

Mw6.1, Dist. $96^{\circ}$, Baz.222 ${ }^{\circ}$

Minimum Energy

Optimal: $\phi=[\quad 86 \leq-88 \leq-84]^{\circ}$ $\delta \mathrm{t}=[1.36 \leq 1.52 \leq 1.68] \mathrm{s}$

Stack: $\phi=[\quad 86 \leq-90 \leq-84]^{\circ}$ $\delta \mathrm{t}=[1.36<1.52<1.68] \mathrm{s}$

Quality: Good Result: Stack

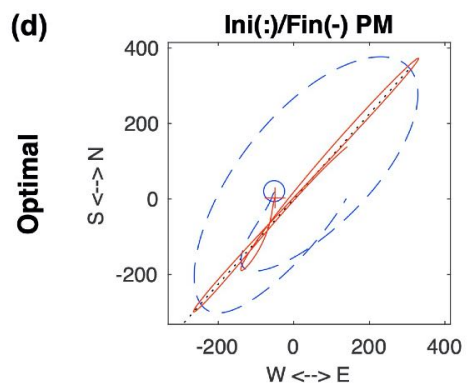

(a)

$\mathrm{x} 1.4510\left(24.35^{\circ}, 106.74^{\circ}\right)$ 20130722(203)07:01:42.7 Mw6.1, Dist. $96^{\circ}$, Baz.222。 Minimum Energy Optimal: $\phi=[78 \leq 84 \leq 88]^{\circ}$ $\delta \mathrm{t}=[1.00 \leq 1.12 \leq 1.24] \mathrm{s}$ Stack: $\phi=[76 \leq 82 \leq 86]^{\circ}$ $\delta \mathrm{t}=[1.00 \leq 1.12 \leq 1.24] \mathrm{s}$ Quality: Good Result: Stack

(d)

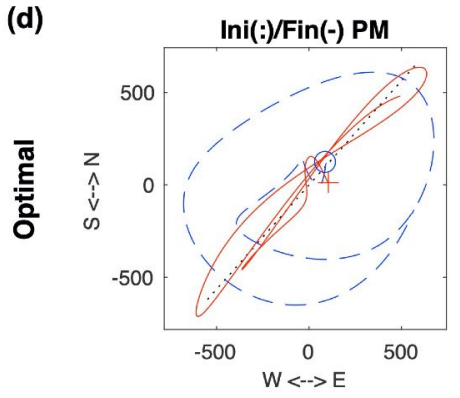

(a)

$\mathrm{x} 1.51020\left(28.35^{\circ}, 105.82^{\circ}\right)$ 20110711 (192) 07:15:43.8 Mw5.9, Dist. $94^{\circ}$, Baz.122 Minimum Energy

Optimal: $\phi=[15 \leq 26 \leq 25]^{\circ}$ $\delta \mathrm{t}=[0.32 \leq 0.84 \leq 0.96] \mathrm{s}$ stack: $\phi=[-54 \leq-27 \leq 21]^{\circ}$ $\delta \mathrm{t}=[0.16<0.24<0.80]$ Quality: Good Result: Null

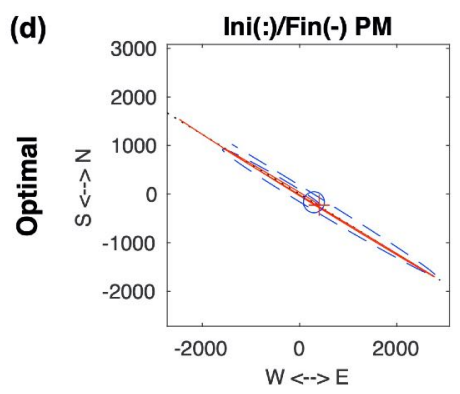

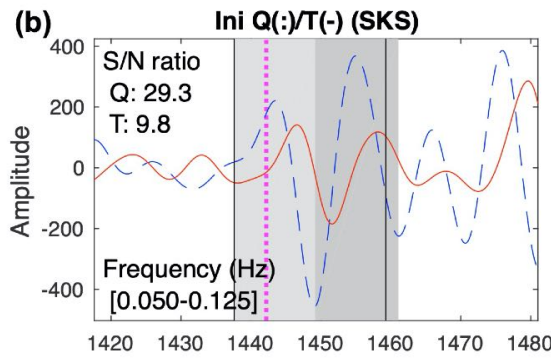

(c) Results of 7 iterations
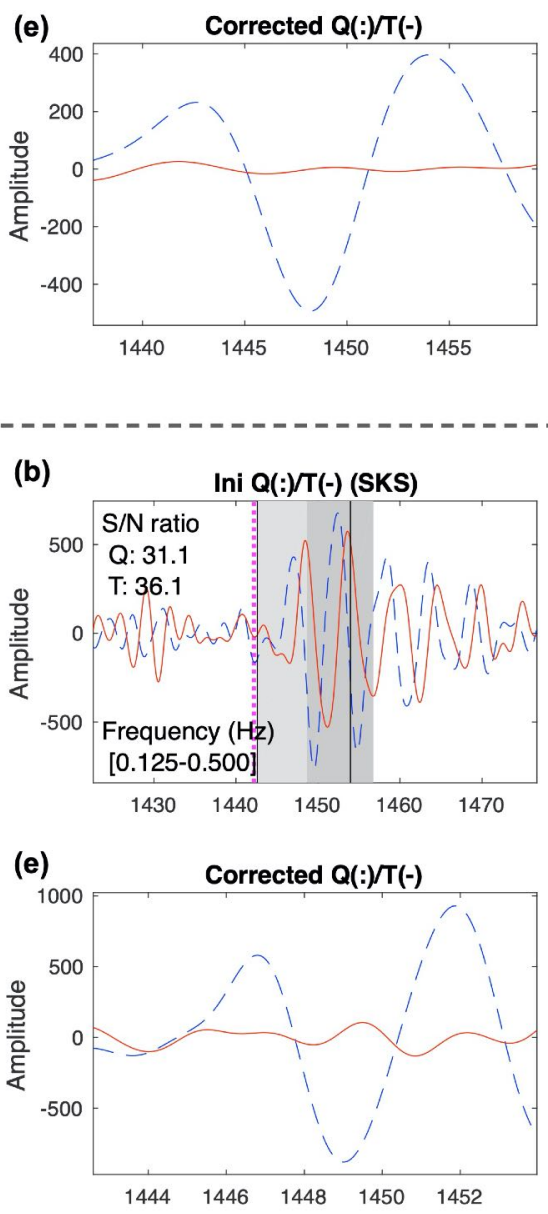

(c)
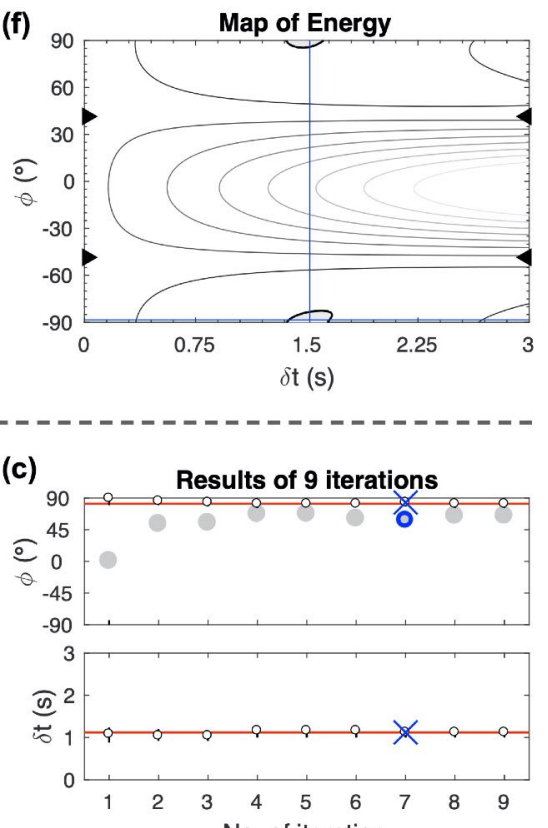

No. of iteration

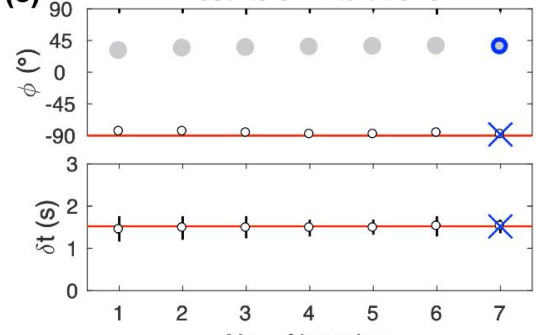

(f)

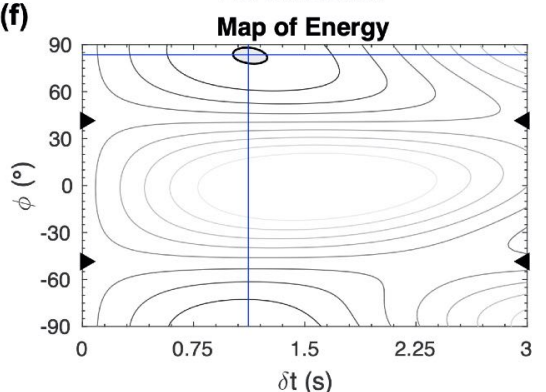

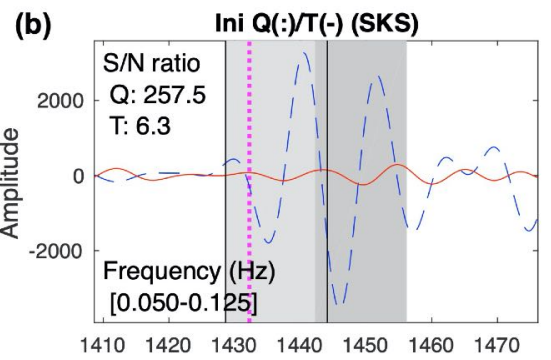

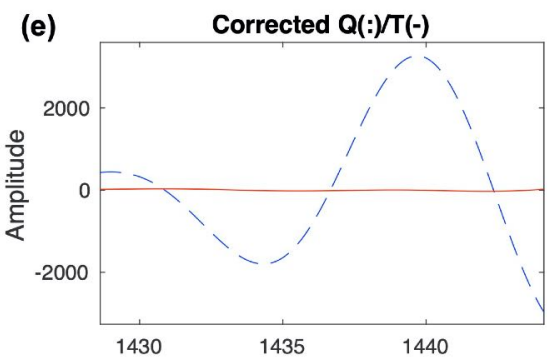

(c)

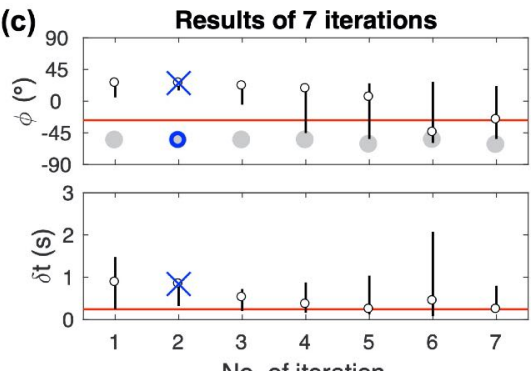

(f)

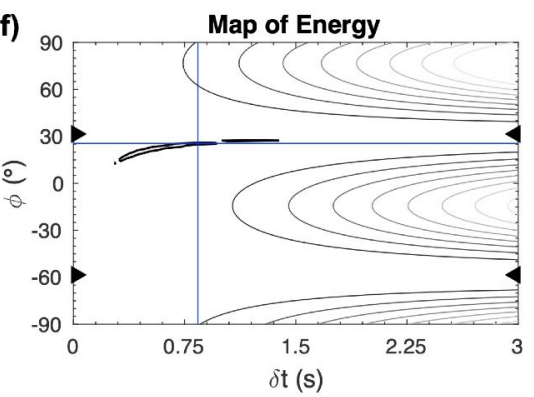


Figure 4

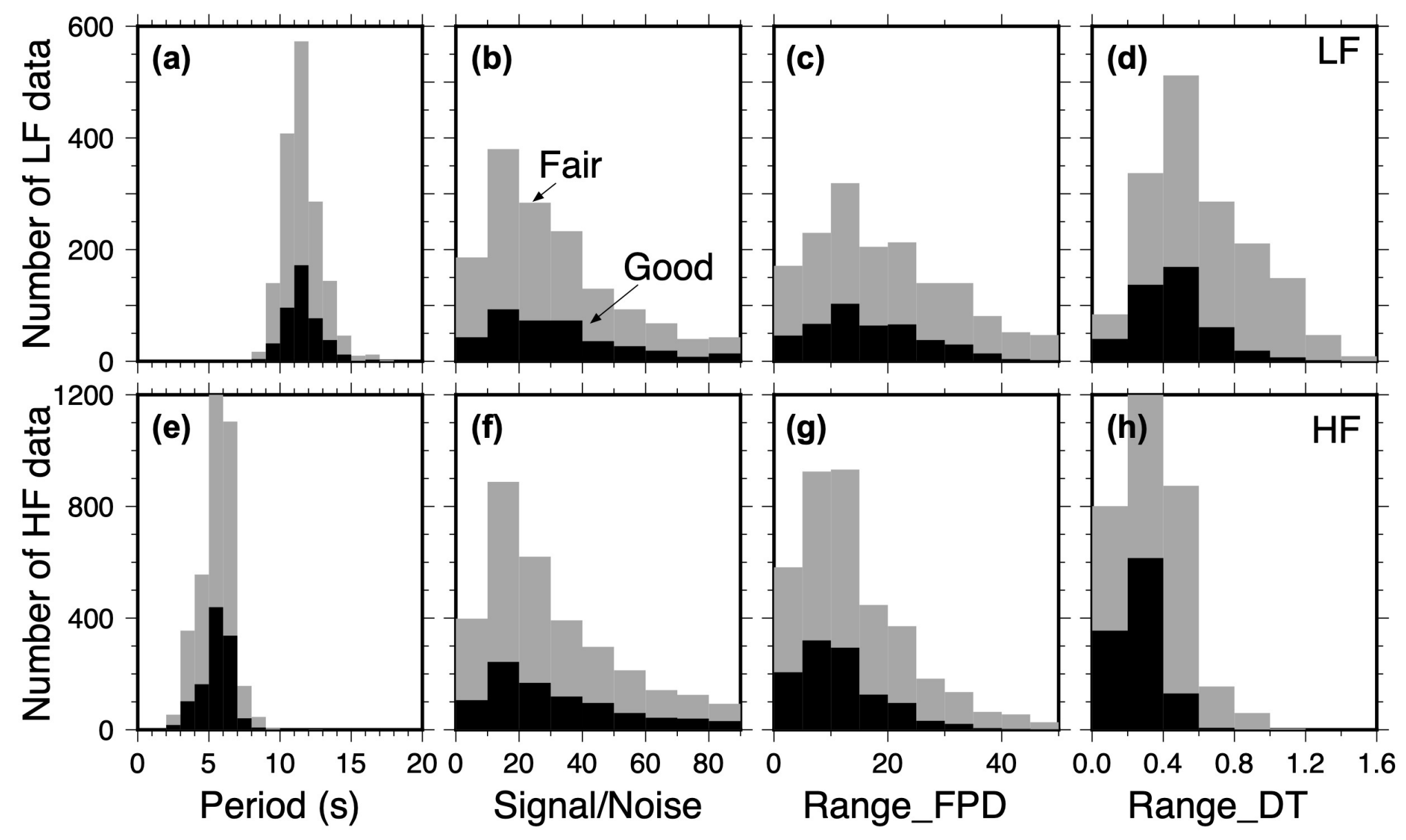


Figure 5

Measurements with minimum-transverse-energy method (8-20 s)
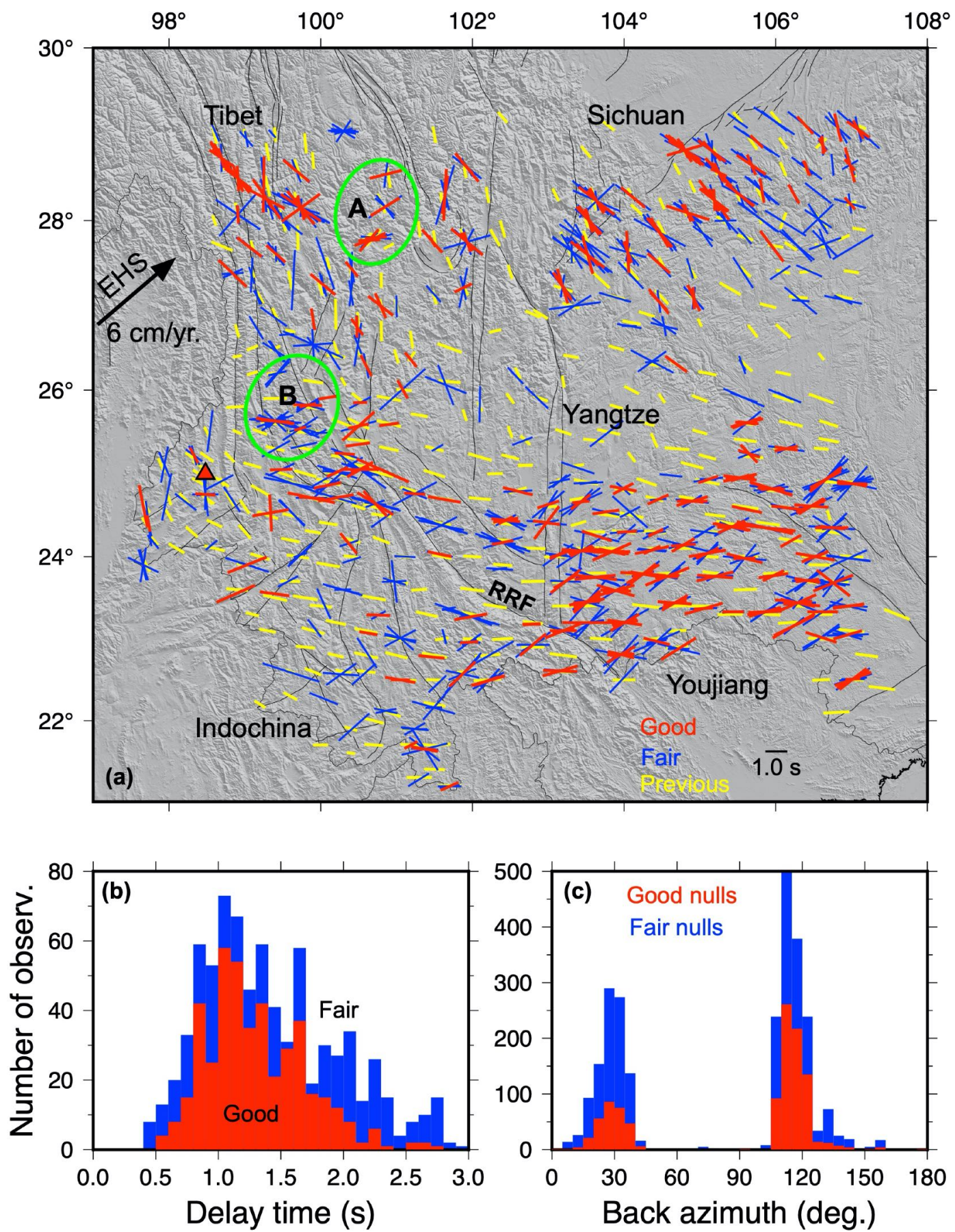
Figure 6

Measurements with minimum-transverse-energy method (2-8 s)
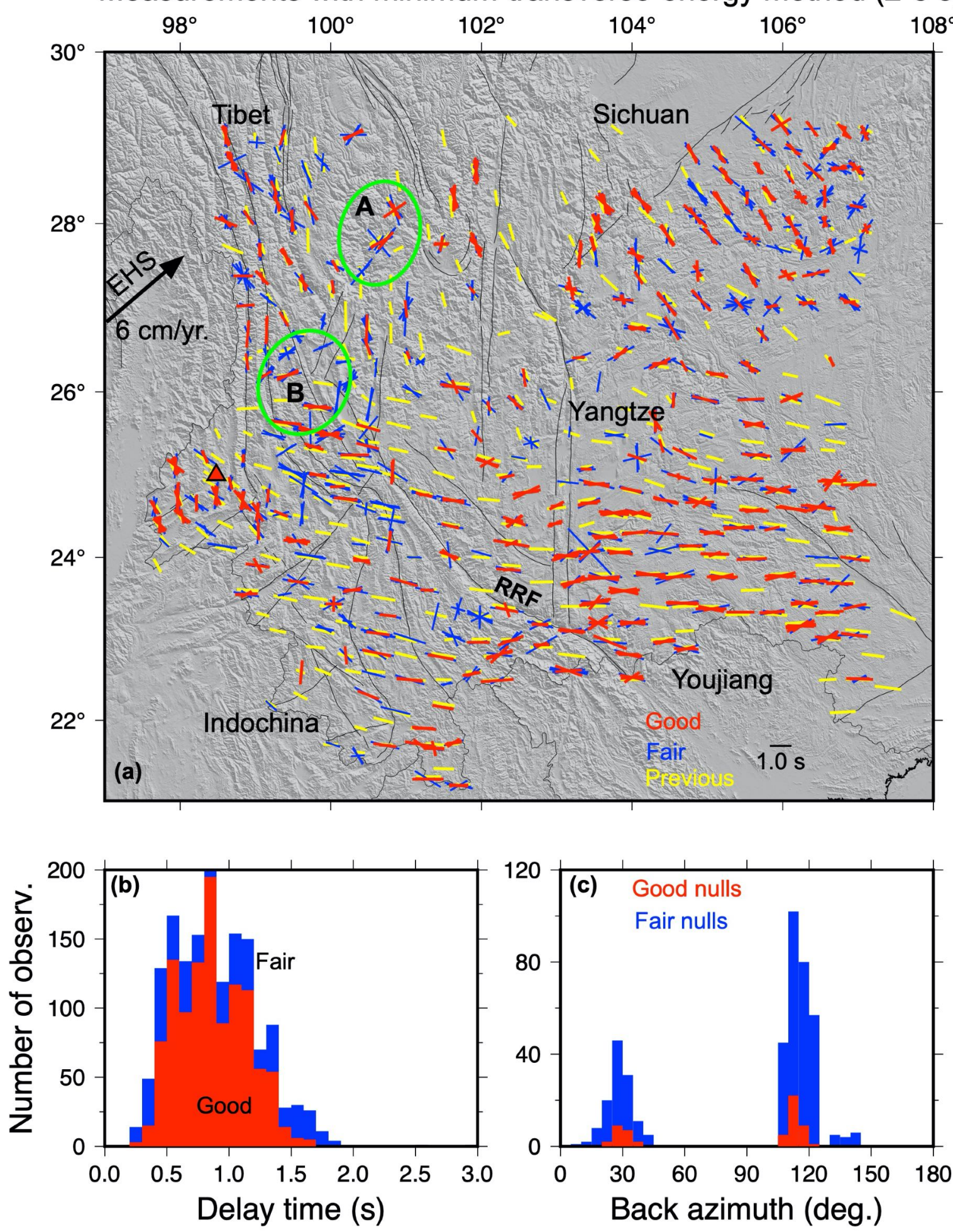
Comparison between high and low frequency measurements
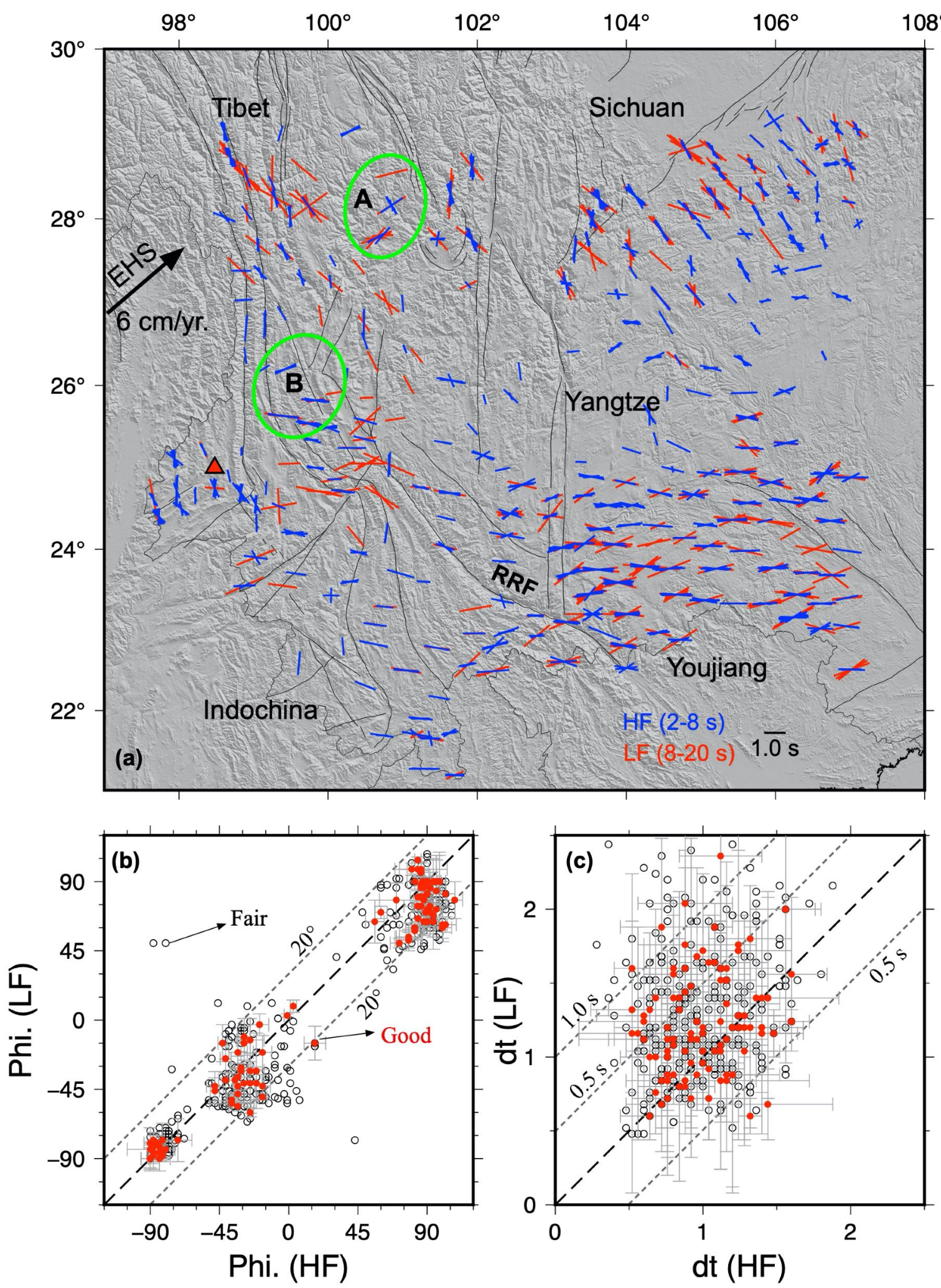
Figure 8

Kernels of splitting intensities

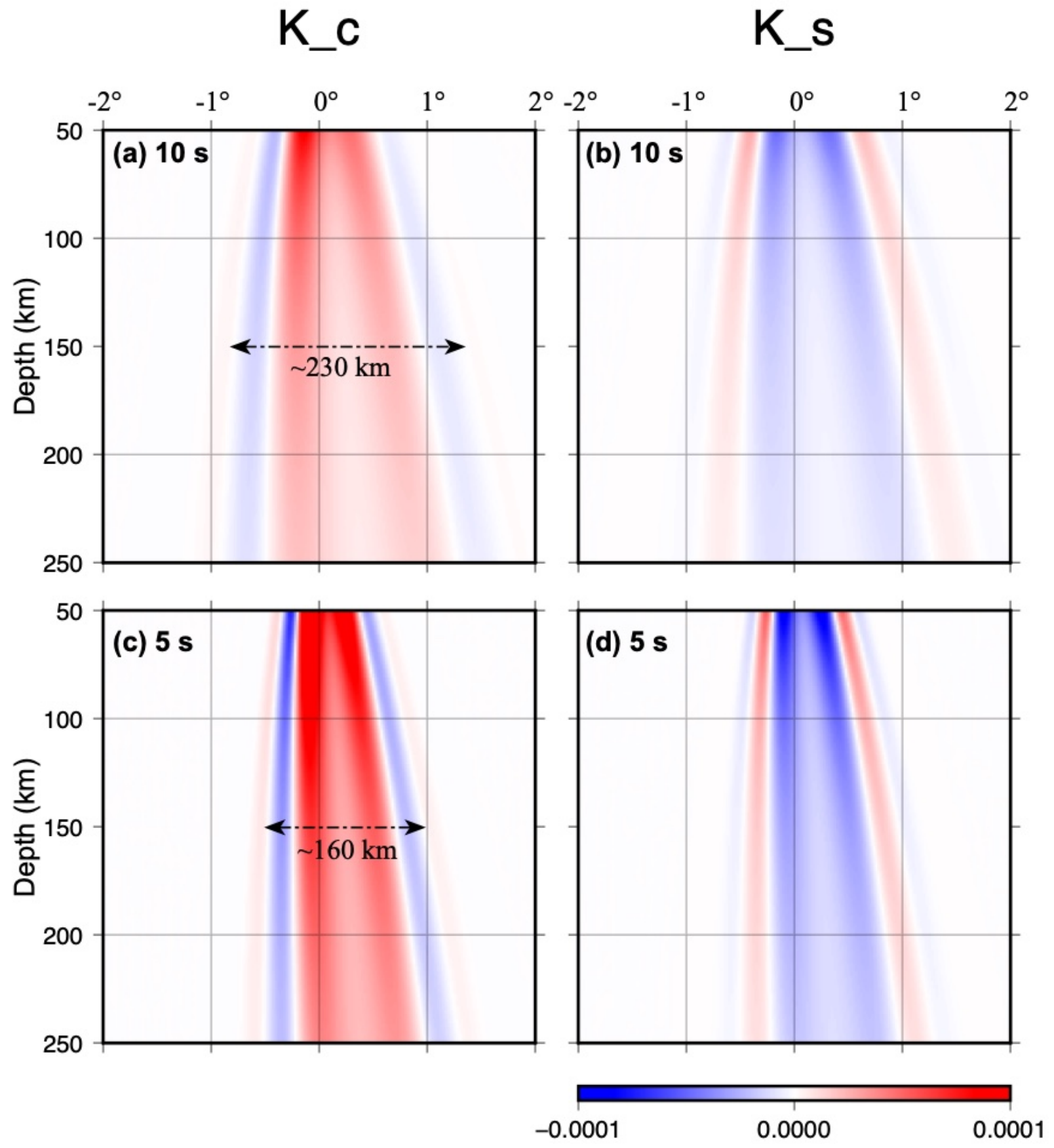


Figure 9
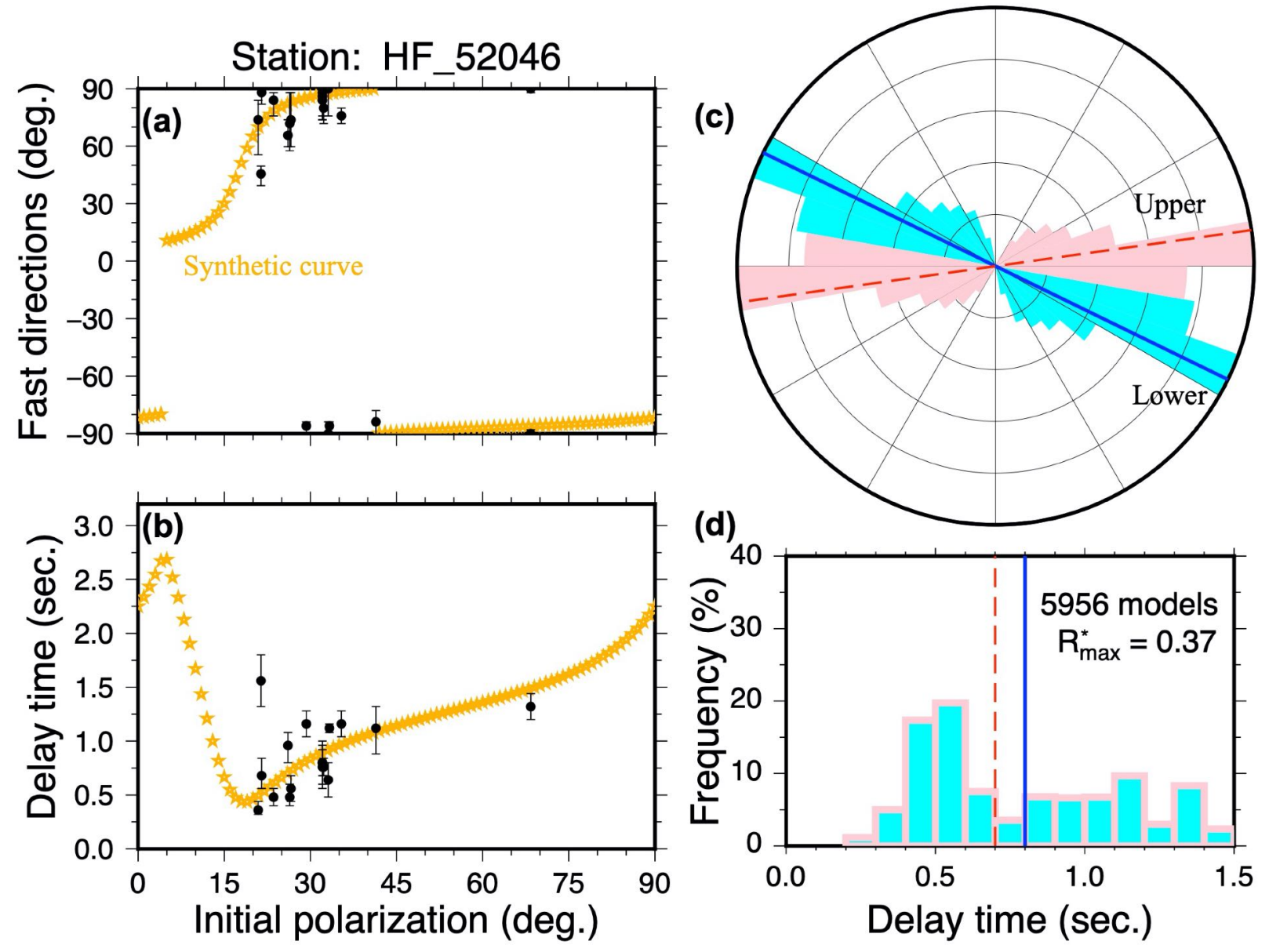
Figure 10

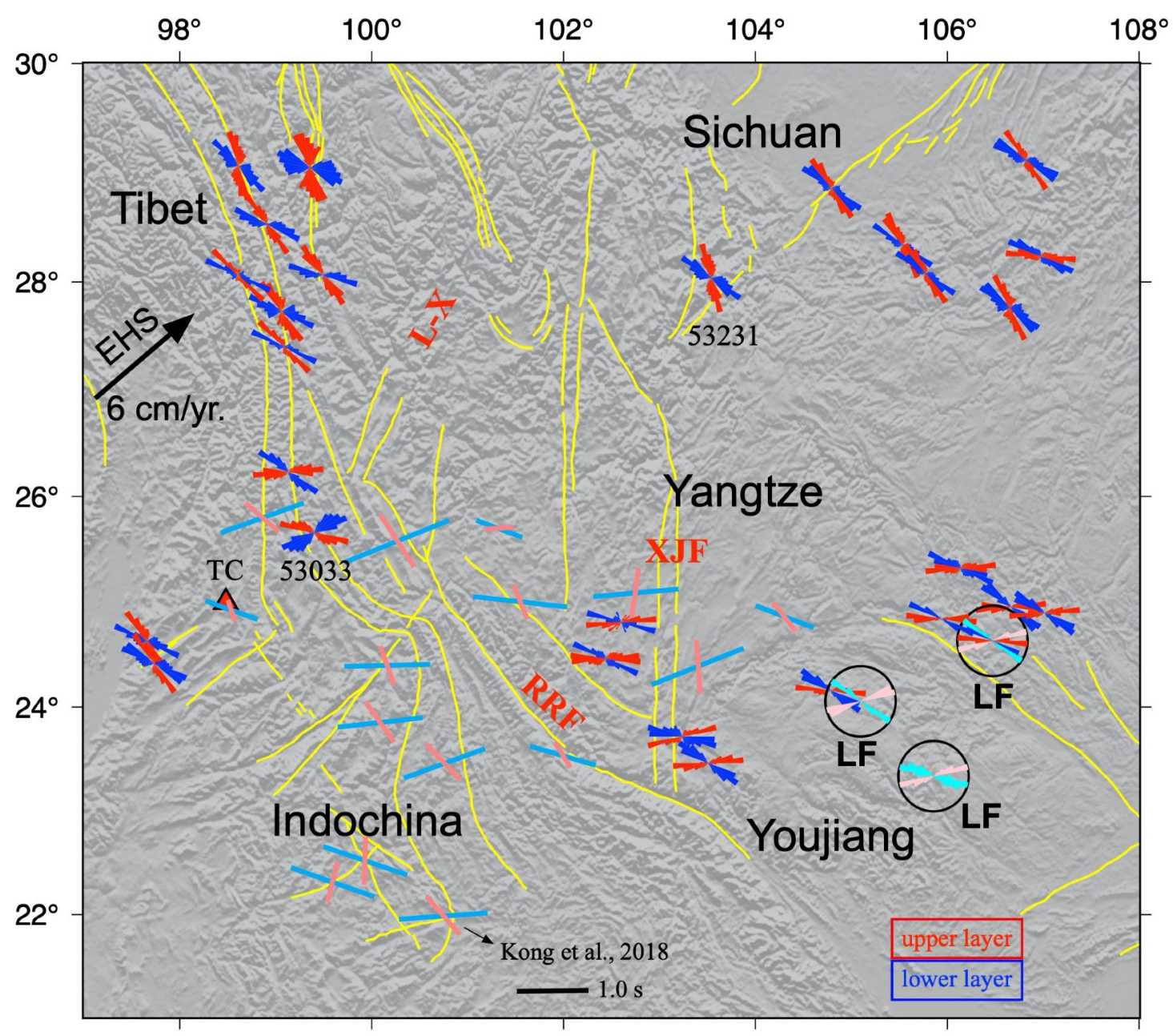



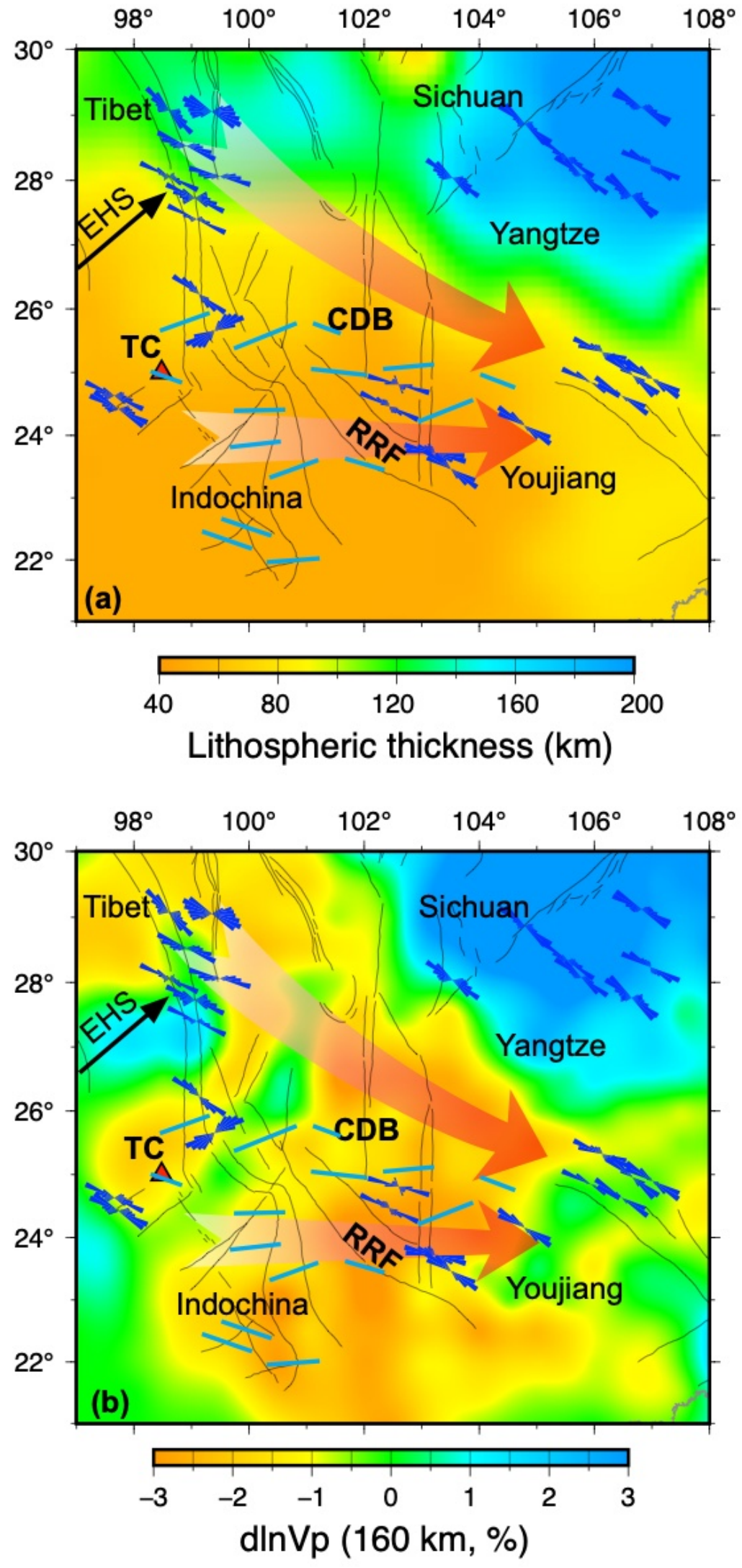